\title{
Mechanism For The Adsorption Of Mucin On Hydroxyapatite
}

\author{
J. A. Lori*, S. Z. Kazaure ${ }^{\dagger}$ and S. M. Dangoggo ${ }^{\dagger}$ \\ * Department of Chemistry, Ahmadu Bello University, Zaria, Nigeria. \\ †Department of Pure \& Applied Chemistry, Usmanu Dan Fodio University, \\ Sokoto; Nigeria
}

\begin{abstract}
The adsorption of mucin onto HA has been investigated with respect to the role of electrostatic interactions, ionic environment, mucin concentration and $p H$. Aqueous solution of Mucin was suspended with treated and untreated HA and the mucin concentration in the supernatant determined. The Langmuir's model was used to analyze isotherm data; the maximum amount of mucin adsorbed and the affinity or association constants were calculated. The presence of added Ca ions increased the amount of mucin adsorbed as well as the association constant. The mechanism of the adsorption of mucin on hydroxyapatite is considered to be related mainly to electrostatic interactions and zeta potential change as well as some hydroaen bondina between the
\end{abstract}

\section{INTRODUCTION.}

The importance of the adsorption of proteins onto hydroxyapatite (HA) in a variety of oral biological events cannot be overemphasised. When biomaterials come into contact with various biological fluids (blood, saliva, tears), protein adsorption at the solid - liquid interface is the first phenomenon, which occurs. Apatites are excellent biomaterials due to their biocompatibility. HA can form a bond with bone and tissue, biological apatite is the main constituent of the hard tissues of bone and teeth. Mucin is a class of glycoproteins characterized mainly by its large molecular weight and high level of O-linked oligosaccharide ${ }^{1}$.
It is the major constituent of mucus in various parts of the body and covers the surfaces of the buccal cavity and epithelial organs. Mucin has been identified in several additional types of dental biofilms such as salivary pellicle on (HA) ${ }^{2}$. Mucin is the major constituent of salivary protein and salivary proteins are selectively adsorbed onto tooth surfaces forming the 'acquired enamel pellicle' ${ }^{3}$. It has been reported that the pellicle influences the initial attachment of microorganisms to the tooth surface and remains interposed between the enamel and dental plaque ${ }^{4}$.

A concise understanding of the mechanism of protein adsorption onto 
HA will contribute immensely to the present trends in caries research, where there is increased interest in the role proteins are playing as potential inhibitors of the enamel or dentine demineralization.

It has been reported that the boneimplant interfaces comprise a so-called bonding zone composed of a calciumand phosphorus-rich proteinaceous matrix ${ }^{5}$. The role of mucous glycoproteins as a macromolecular surfactant is of great importance in the science and technology of biomaterials. Biosurfaces such as dentures are placed on a mucosal surface. Several mechanisms for the human salivary albumin (HSA) adsorption to biomedical polymers have been reported ${ }^{6-}$ ${ }^{10}$. However, reports on the mechanism of mucin adsorption on these biomedical materials are virtually not available.

This report details an in vitro study that investigated

i) the affinity of mucin to HA particles,

ii) the effect of the surrounding ionic composition and $\mathrm{pH}$ on the adsorption process and

iii) using these results to suggest a probable mechanism for the adsorption of mucin onto HA.

\section{MATERIALS AND METHODS Materials}

HA was obtained from Sigma Chemical Co. (pproximately $25 \%$ solid suspended in $0.001 \mathrm{M}$ phosphate buffer and $\mathrm{pH}$ 6.8 ). $4 \mathrm{ml}$ of the suspension yielding $1.1 \mathrm{~g}$ dry weight of the solid HA. The calcium/phosphate ratio was 1.63 and surface area $25 \mathrm{~m}^{2} \mathrm{~g}^{-1}$. The HA used in these studies is termed 'Calcium deficient'. Mucin powder was obtained from Nacalai Tesque Inc., Kyoto, Japan mucin $(1.0 \mathrm{~mL}, 2.0-15 \mathrm{mg} / \mathrm{mL})$ was added (lyophilized powder, analytical grade). It was used without further purification.

\section{Methods}

$0.2 \mathrm{~mL}$ of mucin supernatant was transferred to a test tube containing 5.0mL Bradford reagent (Biorad, Richmond, CA) and the total volume adjusted to $8.0 \mathrm{~mL}$ with doubly distilled water according to the Bradford assay ${ }^{11}$. Absorbance was measured at $595 \mathrm{~nm}$ with a Spectronic 20 uv-visible spectrophotometer (Bausch \& Lomb Co., NY). The concentration of mucin was calculated according to a standard solution of bovine serum albumin, BSA (Sigma Chemical Co.). HA suspended in doubly distilled water served as control. $\mathrm{HA}$ was suspended in $0.01 \mathrm{M} \mathrm{CaCl}_{2}$, $0.01 \mathrm{M} \mathrm{NaCl}$, and $0.01 \mathrm{M} \mathrm{Na}_{2} \mathrm{HPO}_{4}$ for 4 $\mathrm{h}$ at room temperature. The HA was washed with doubly distilled water and used in investigating the effect of these ions on the adsorption of mucin on HA.

One way ANOVA with Dunnett's post test was performed using Graphpad Prism version 3.00 for Windows ${ }^{12}$.

\section{RESULTS AND DISCUSSION}

\section{Adsorption Isotherms}

The amount of adsorbed protein was calculated by subtracting the amount of unadsorbed (free) protein in the supernatant from the amount of protein in the control (mucin not suspended in HA powder) and plotted in the form of a Langmuir adsorption isotherm as shown in Figure 1.

The maximum amount of adsorbed mucin and the mucin-HA association constant were calculated according to the slope and the x-intercept, respectively, of the linear curve:

$$
\mathrm{F} / \mathrm{B}=1 / \mathrm{K} \alpha \mathrm{N}+1 / \mathrm{N} . \mathrm{F}
$$


To $0.02 \mathrm{~g}$ of $\mathrm{HA}$ all experiments were in Triplicates) and incubated for $2 \mathrm{~h}$ at $37^{\circ} \mathrm{C}$. where

$\mathrm{B}=$ bound mucin, $\mathrm{F}=$ free mucin, $\mathrm{K} \alpha=$ association constant and $\mathrm{N}=$ maximum amount of mucin adsorbed.

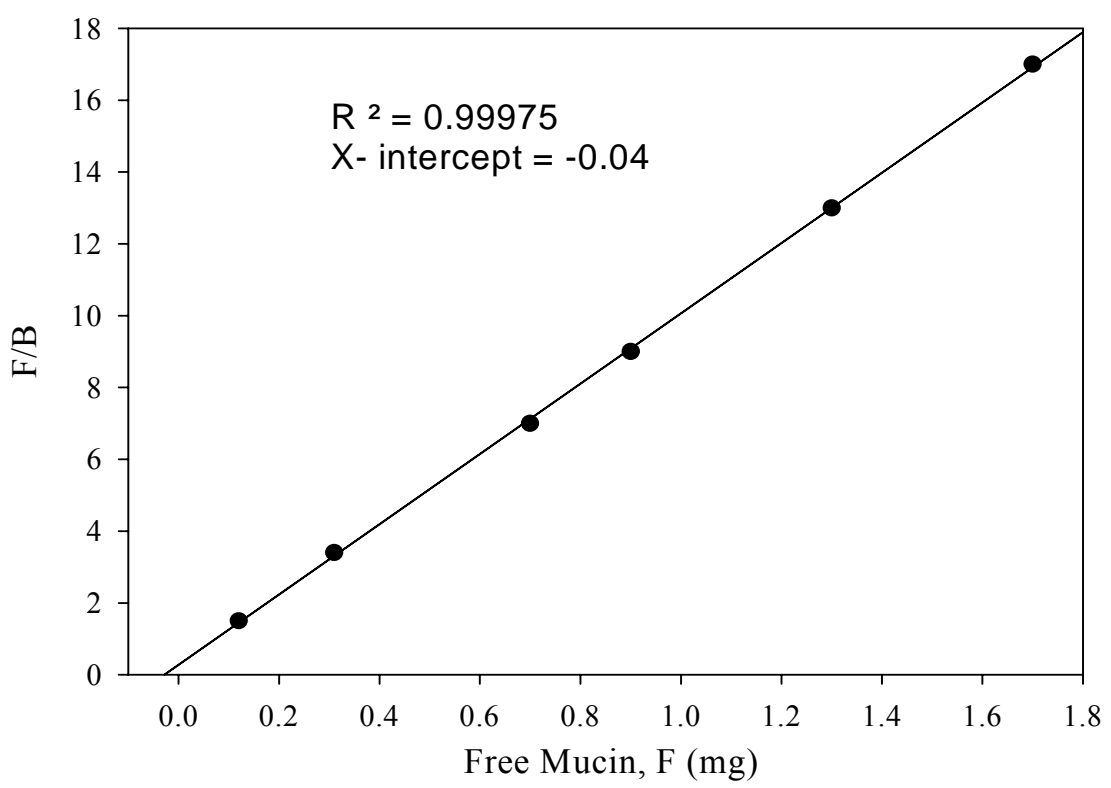

Figure 1: Langmuir adsorption Isotherm of Mucin adsorbed on hydroxyapatite

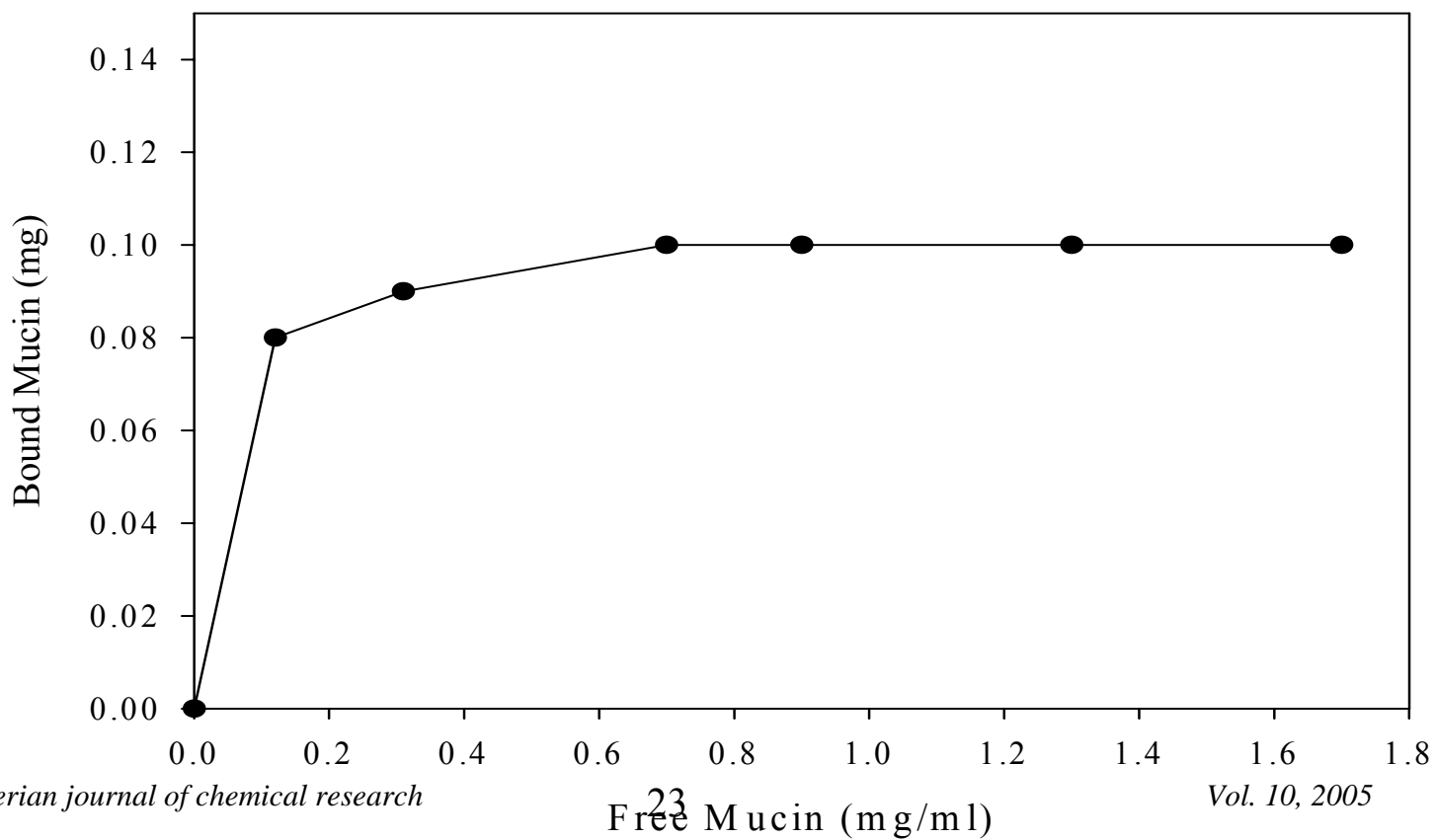

Figure 2: Adsorption Isotherm of Mucin to Hydroxyapatite 


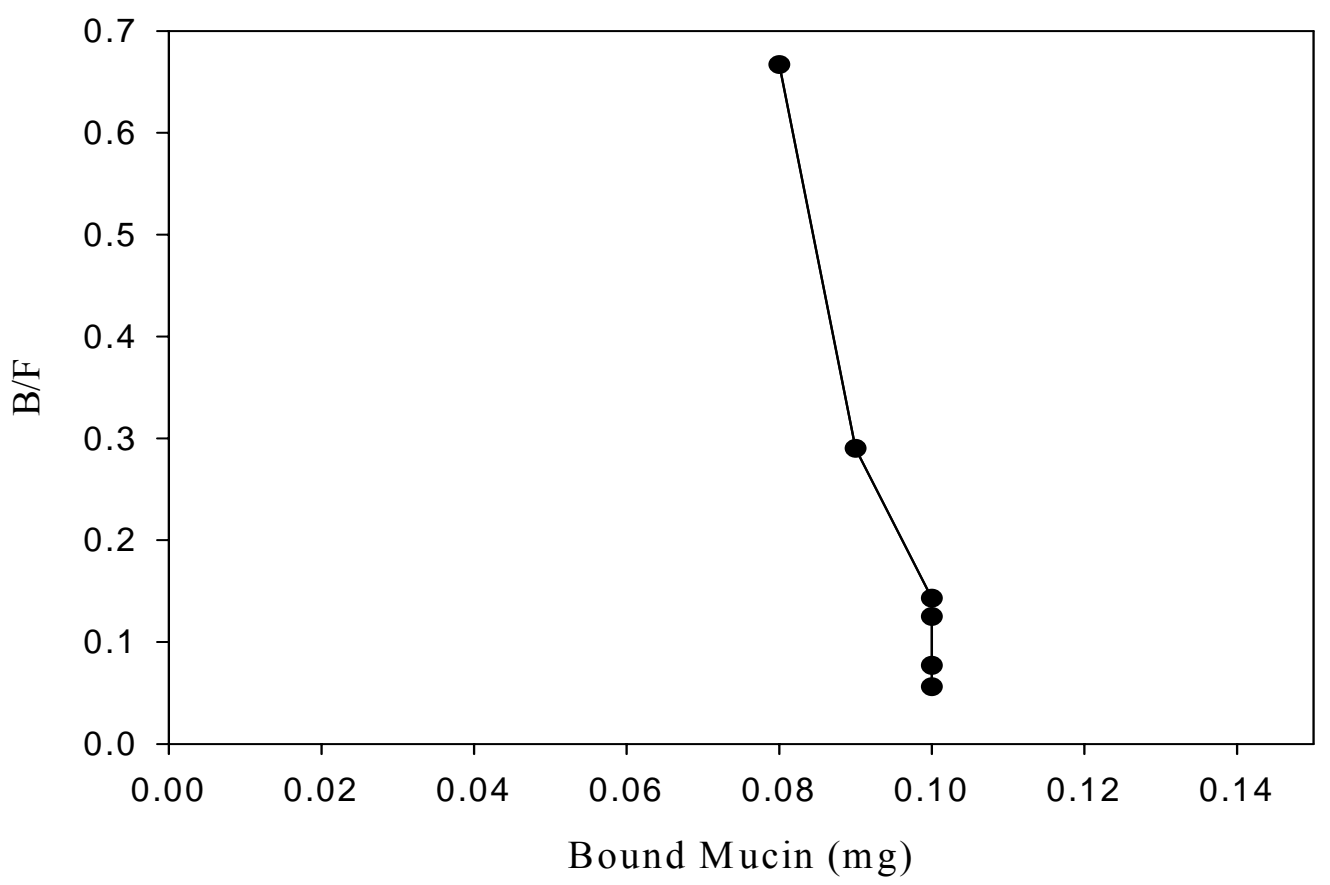

Figure 3: Scatchard Plot demonstrating lack of linearity in the adsorption of mucin on hydroxyapatite powder.

Figure 2. shows the typical adsorption concentration of mucin was increased, isotherm of mucin to HA powder. As there was an initial rapid adsorption followed by a slower approach to a limiting value of $0.95 \mathrm{mg} / \mathrm{mL}$.

The maximum amount of mucin adsorbed and the affinity between the mucin molecule and the HA surface were calculated according to the Langmuir adsorption isotherm in Figure 1. A maximum of $0.104 \mathrm{mg}$ mucin was adsorbed per gram of HA ( $\mathrm{N}=1 /$ slope) and the mucin-HA association constant was $0.04 \mathrm{~mL} / \mathrm{mg}\left(\mathrm{K}_{\alpha}=-\mathrm{x}\right.$ intercept $)$. However, a Scatchard plot shown in Figure 3 revealed a lack of linearity in the data. This implies a positive cooperativeness and probably the existence of additional binding sites.

calcium sites for adsorption and this was increased by the calcium ion treatment

\section{Effect of Ions.}

Binding occurred with HA not treated with calcium ions, though a positive correlation was observed as a result of the presence of calcium ions and the extent of mucin adsorption. HA has its own native

which has put the calcium ions more on the surface of HA.

The effect of incubation time on the adsorption of mucin in the absence and 
presence of calcium ions is shown in Figure 4. presence of calcium ions. Equilibrium adsorption was attained within $4 \mathrm{~h}$ as

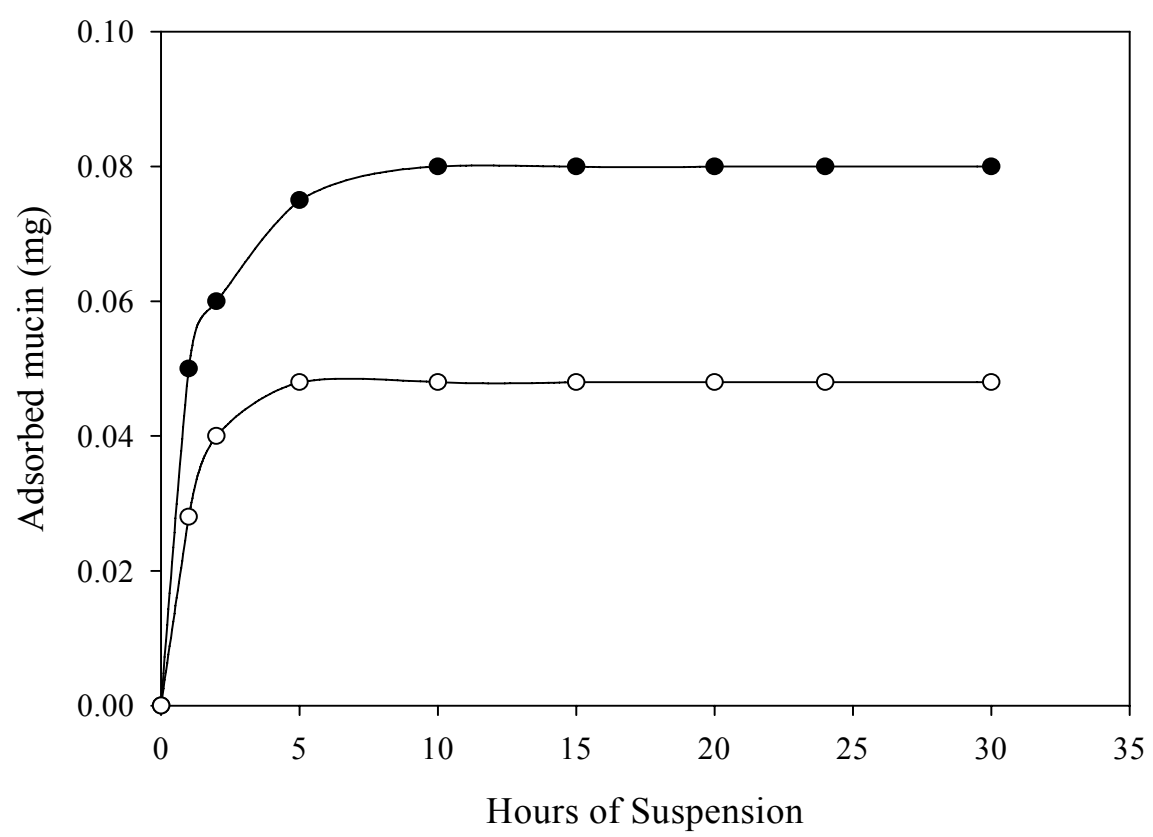

Figure 4: Effect of incubation time on the adsorption of mucin in the presence(-๑) and absence $(-$ )of Calcium ions

The results obtained show that most of shown in Figure 4. the adsorbed mucin $(>80 \%)$ was adsorbed within $1 \mathrm{~h}$ in either the absence or

The results of the use of HA treated with $\mathrm{NaCl}, \mathrm{CaCl}_{2}$ and $\mathrm{Na}_{2} \mathrm{HPO}_{4}$ for binding studies with mucin are shown in Figure 5. The Y-axis is expressed as the amount of

Generally, the amount of unadsorbed mucin in the supernatant fluid decreased following the suspension of mucin in calcium treated HA. There was very little adsorption as a result of HA treatment with $\mathrm{NaCl}$ and less than the control amount was adsorbed as a result of treatment with $\mathrm{Na}_{2} \mathrm{HPO}_{4}$. Mucin is an acidic protein and will therefore have a net negative charge at pH 7.0 or higher. This means that it will bind to the calcium groups of HA through its $\mathrm{COOH}$ groups. The binding of these mucin adsorbed to untreated HA which served as the control in this case subtracted from the amount of mucin adsorbed to the treated samples.

sites may expose the $\mathrm{NH}_{3}{ }^{+}$group that will bind to the phosphate groups of HA forming weak hydrogen bonds. $\mathrm{Na}^{+}$may compete with $\mathrm{NH}_{3}{ }^{+}$groups for the phosphate sites on HA. There was no significant difference $(\mathrm{P}<0.05)$ in the amount of mucin adsorbed to HA in the presence or absence of $\mathrm{NaCl}$. It has been reported that $\mathrm{Na}^{+}$has a weak affinity for BSA and $\mathrm{HA}^{13}$, therefore bridging effect observed with divalent calcium may be absent or negligible. 
Phosphate addition makes HA more negatively charged due to surface adsorption $^{14}$. The phosphate groups are reported to have a higher affinity for HA surfaces than the $\mathrm{COOH}$ groups of proteins $^{15}$. The parameters for the adsorption of various amino acids onto $\mathrm{HA}^{16}$ indicate that the strength of the phosphate bond is more than 20 times greater than that of the carboxyl bond. The more hydrophilic nature of the phosphates removes water from HA surfaces upon adsorption. The level of mucin adsorbed on HA pretreated with $\mathrm{Na}_{2} \mathrm{HPO}_{4}$ is therefore probably due to the successful competition of phosphate for the calcium groups of HA thereby lowering the number of binding sites ordinarily available to mucin on an untreated HA. The results for $\mathrm{Na}_{2} \mathrm{HPO}_{4}$ in Figure 5 was therefore not without cause.

\section{pH dependence and effect}

The net electric charge of a protein depends on its isoelectric $\mathrm{pH}(\mathrm{pI})$ and the $\mathrm{pH}$ of the environment. The $\mathrm{pH}$ of mucin solution in distilled water was 4.6-4.9. Mucin undergoes a neutral - acid transition and becomes negatively charged at higher $\mathrm{pH}$ values while at lower $\mathrm{pH}$ values mucin undergoes a neutral-basic transition and becomes positively charged. Also, the isoelectric point of HA has been found to be between $\mathrm{pH} 6.4$ and 8.5 depending on the experimental methods used ${ }^{14,17-18}$. Since a high solid/liquid ratio is expected for the in vivo situation, in our present work, a solid/liquid ratio of $20 \mathrm{~g} \mathrm{~L}^{-1}$ of HA was used. This means that at $\mathrm{pH} 7.0$ the zetapotential for our HA system will be positive $^{14,18}$.

Because mucin is negative in the $\mathrm{pH}$ region (7.0) that we worked in principally, electrostatic attraction played a very prominent role in the interaction of mucin with HA surface. This is substantiated by the results shown in Figure 6. At a lower $\mathrm{pH}(3.0)$, the mucin molecules are positively charged, this makes the presence of $\mathrm{Ca}^{2+}$ ions irrelevant to the adsorption of mucin to HA surface. This can also be explained by the shift in the zeta-potential of HA at these $\mathrm{pH}$ values.

At $\mathrm{pH}$ 7.0, the negatively charged mucin molecule and the HA surface makes the bridging action of the divalent calcium ions very relevant and increased adsorption resulted as shown in Figure 6 and illustrated in Figure 7. Mucin is mainly adsorbed by electrostatic attraction between the $\mathrm{COOH}$ group of mucin and the calcium ion on the surface of HA. It has been reported that when labelled calcium and phosphate ions are added to HA, only phosphate ions are released when acidic proteins are adsorbed. Acidic proteins therefore exchange with phosphate and are adsorbed to the calcium ions ${ }^{19}$. The neutral and positive parts of mucin bind less strongly to HA. 


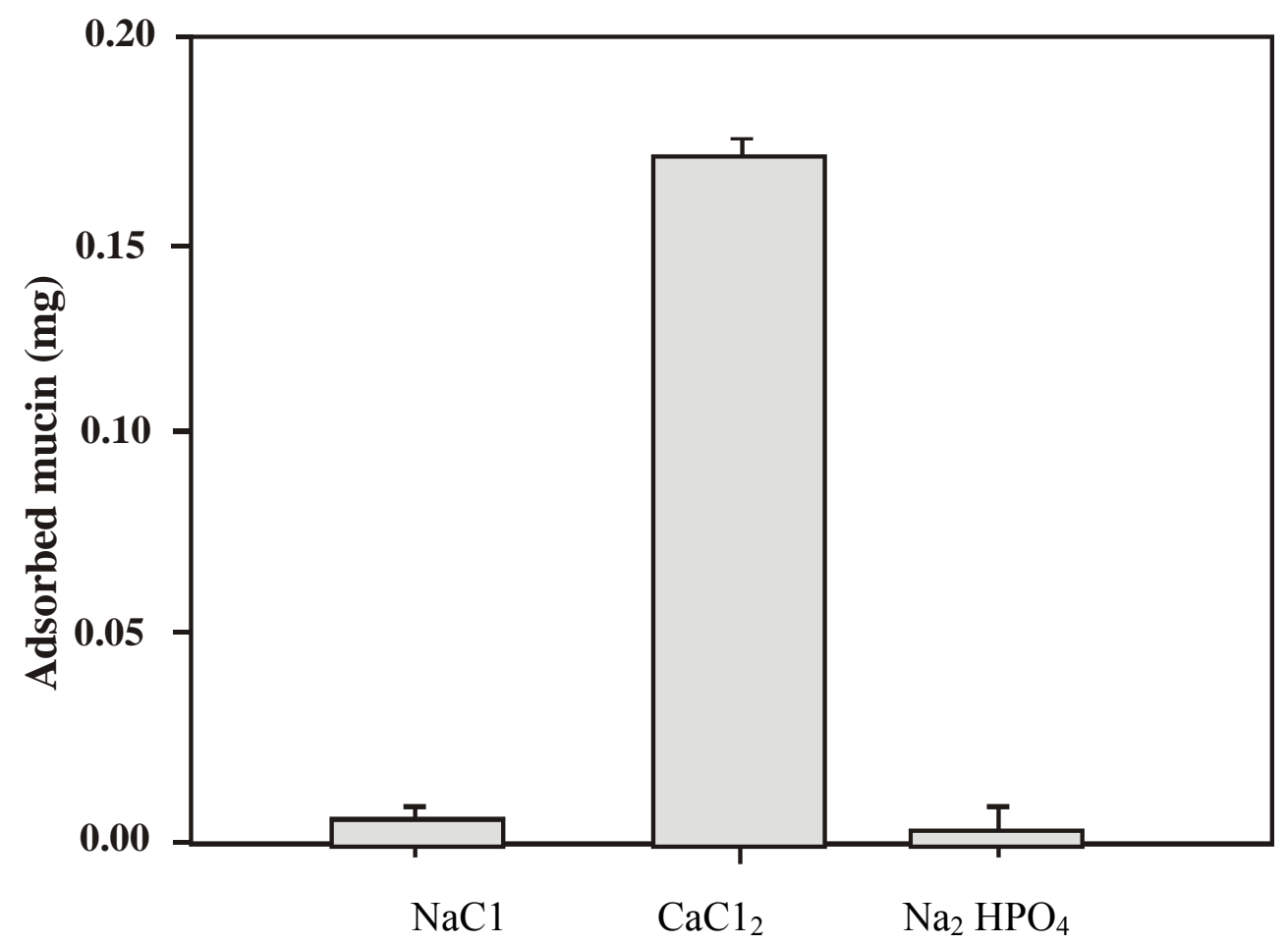

Figure 5: The adsorption of $1.0 \mathrm{mg} / \mathrm{m} 1$ mucin to hydroxyapatite with $\mathrm{CaCl}_{2}, \mathrm{KCl}$ or $\mathrm{Na}_{2} \mathrm{HPO}_{4}$

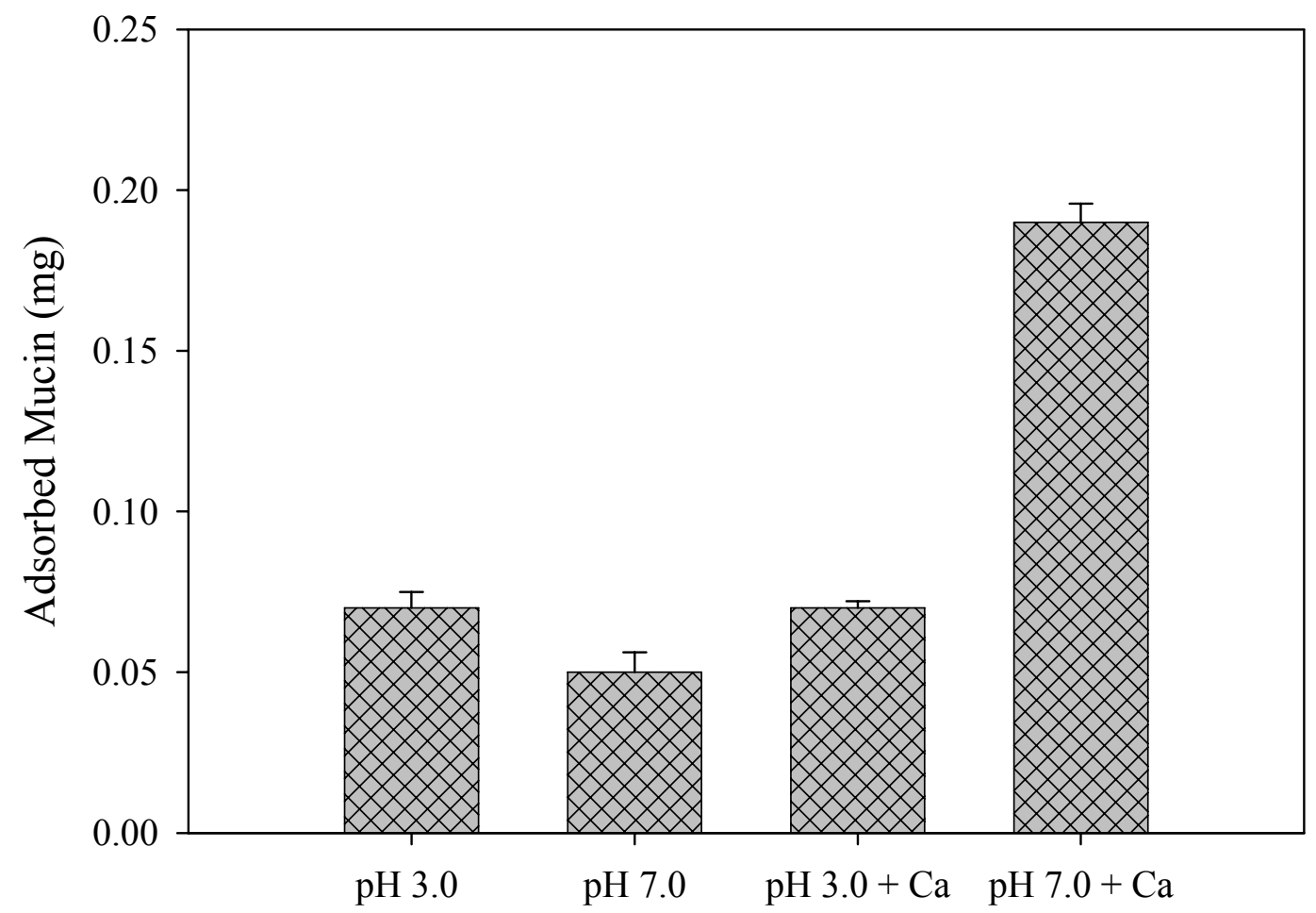

Figure 6: The adsorption of $1.0 \mathrm{mg} / \mathrm{ml}$ mucin to untreated and calcium-treated hydroxyapatite at $\mathrm{pH} 3.0$ or 7.0 . 


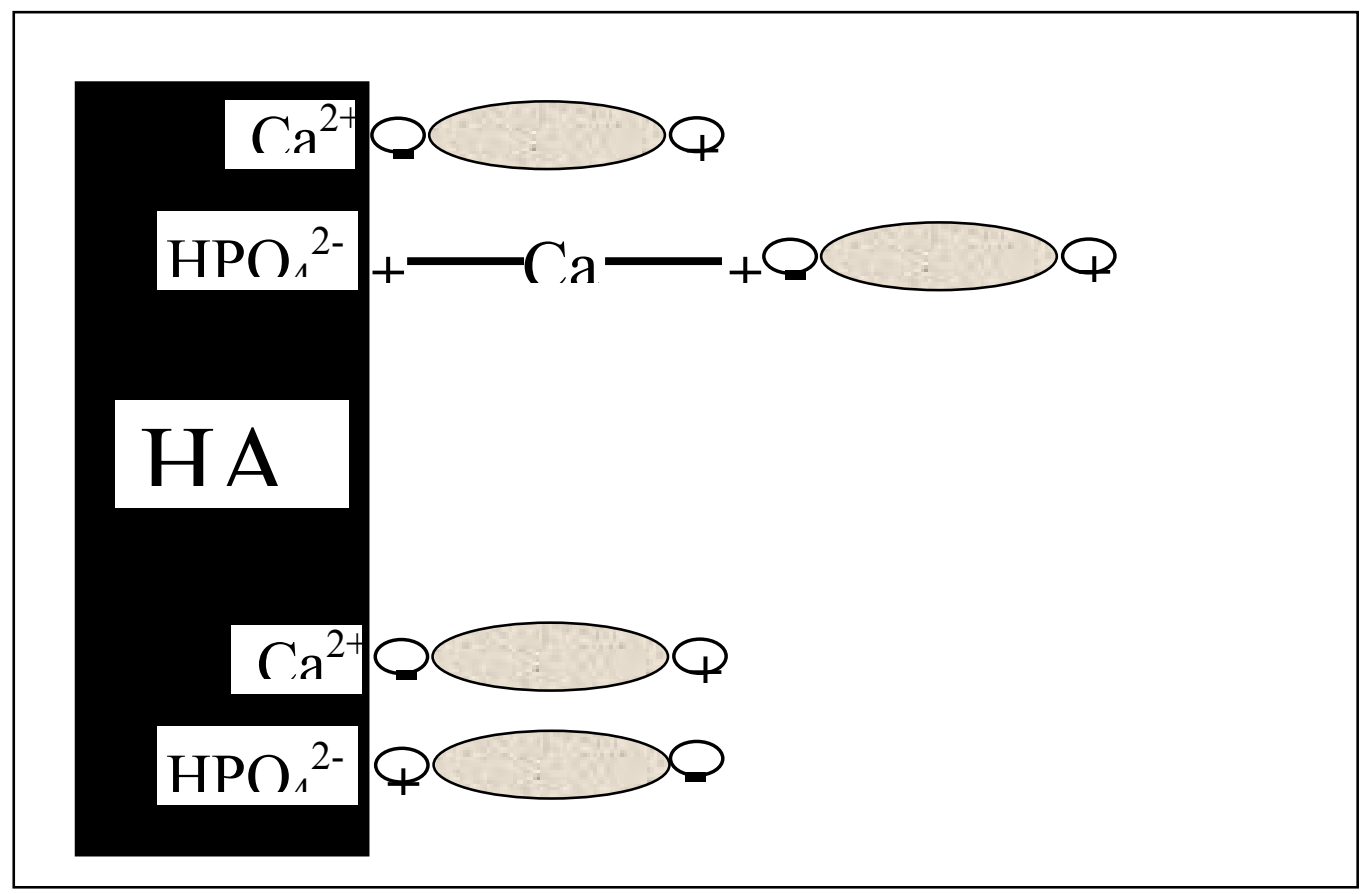

Figure 7: The possible mechanisms for the initial adsorption of mucin to Hydroxyapatite.

\section{CONCLUSION}

This work has provided important information to contribute to the understanding of the mechanism of the adsorption of mucin onto HA. The Langmuir model describes the adsorption process. Sodium ions made no difference while phosphate ions decreased the amount of mucin adsorbed on HA. Under physiological conditions ( $\mathrm{pH} 7.0-7.4$ ), the mucin molecule binds calcium ion to its electrostatic sites. These calcium ions serve as ligands between the negatively charged mucin molecules and the HA surface (Figure 7). In the light of calcium's abundance in the saliva and $\mathrm{pH}$ variation constantly occurring during and between meals, this study is very relevant to the mechanism of the binding of salivary component (mainly mucin) to HA structures in vivo.

\section{REFERENCES}

1 Strous, G. J. and Dekker, J. Crit. rev. Biochem. \& Mol. Biol. 27 (1992) 57

2 Rolla, G., Ciardi, J.E. andBowen, W. H., Scand. J. Den. Res. 91 (1983)186.

3 Mayhall, C. W., Arch. Oral Biol., 15 (1970)1327.

4 Hillman, J. D., Van Houte, J. and Gibbons, R. J., Arch. Oral Biol., 15 (1970) 899.

5 Van Blitterswijk, C. A., Grote, J. J., Kuijpers, W., Blok-van Hoek,C. J. G. and Deams, W. T. H., Biomaterials 6 (1985) 243. 
6 Lee, J.Y., Sojar, H. T. Bedi, G. S. 13 and Genco, R. J., Infections \& Immunology 60 (1992) 1662.

7 Xie, H., Gibbons, R. J. and Hay, D. I., Oral Microbiology \& Immunology 6 (1991) 257.

8 Gombotz, W.R., Wang, G. H., . Horbett, T. A. and Hoffman, A. S., J. Biomedical Mat. Res. 25 (1991) 1547.

9 Keogh, J. R., Velander, F. F. and Eaton, J. W., J. Biomedical Mat. 16 Res. 26 (1992) 441.

10 Sevastianov, V. I. In: Szycher, M., ed.,High Performance Biomaterials, p.313, Lancaster, 1995,

11 Bradford, M. M. Anal. Biochem, 72 (1976) 248.

12 H. J. Motulsky, Analysing Data with GraphPad Prism, Graphpad Software Inc., San Diego, CA. www.graphpad.com. 1999.
Shimbayashi, S., Fukuda, H., Aoyama, T. and Nakagaki, M. Chem. Pharm. Bull. 30(1982) 3074.

14. Somasundaran, $P$ and Wang, $Y$. H. C., In: Misa, D. N., ed. Adsorption and Surface Chemistry of Hydroxyapatite, p.129, New York, 1984.

15 Shimbayashi, S., Tanizawa, Y. and Isida, K., Chem. Pharm.

Bull. 39(9) (1991) 2183.

16 Monero, E. C., Kresak, M. and Hay, D. I., Calcif Tissue Int 36 (1984) 48

17 Doss, S. K., J. Dent Res 55(6) (1976) 1067.

18 Arends, J., J Dent. 7(3) (1979) 246.

19 Rolla, G., Ciardi , J. E. and Bowen, W. H. In: Frank, R.M. and Leach, S. A., eds. Surface and Colloid Phenomena in the Oral Cavity: Methodological aspects, London, 1982.

Accepted 8/6/2005

Received 5/2/2005

14 Somasundaran, P. and Wang, Y. 